\title{
4. OS LIMITES JURÍDICO-MORAIS DE CONTRATAR EM “O MERCADOR DE VENEZA”
}

\author{
4. THE LEGAL AND MORAL LIMITS OF CONTRACTING ON "The MERCHANT OF VENICE"
}

\author{
Fábio Caprio Leite de Castro ${ }^{1}$ \\ Ney Wiedemann Neto ${ }^{2}$
}

\begin{abstract}
Resumo: O texto examina a peça "O Mercador de Veneza", de William Shakespeare, e a sua atualidade, numa aproximação entre o Direito e a Literatura, com foco nos limites morais do direito de contratar.
\end{abstract}

Palavras-chave: "O Mercador de Veneza". William Shakespeare. Direito. Literatura. Liberdade. Contrato.

Abstract: The text examines the work "The Merchandt of Venice" by William Shakespeare, and its actuality, a rapprochement between Law and Literature, focusing on the moral limits of the right to contract.

Keiyords: "The Merchandt of Venice" William Shakespeare. Law. Literature. Liberty. Contratc.

\section{Introdução}

O Mercador de Veneza, peça considerada pela crítica como uma das "altas comédias" de William Shakespeare, ${ }^{3}$ recebeu ao longo do tempo inúmeras interpretações. A personagem marcante da peça é o judeu Shylock, que domina a cena ao exigir o pagamento de uma dívida por meio de uma libra de carne. Essa temática não era desconhecida do público inglês à época em que a peça foi escrita, entre 1596 e 1597. Harold Bloom refere o infeliz caso do médico da Rainha Elizabeth, o judeu português convertido ao cristianismo, Dr. Lopez, que foi falsamente acusado de tentar envenená-la, sofrendo a pena de enforcamento e esquartejamento. ${ }^{4} \mathrm{O}$ caso teria motivado Christopher

\footnotetext{
${ }^{1}$ Advogado. Doutor em Filosofia pela Université de Liège (Bélgica). Professor da Faculdade de Filosofia da PUCRS e da Faculdade de Direito da Uniritter. E-mail: facaprio@hotmail.com

2 Desembargador do Tribunal de Justiça do Rio Grande do Sul. Mestre em Poder Judiciário, FGV Direito Rio. Professor do Curso de Direito da Faculdade Inedi CESUCA, Cachoeirinha-RS. E-mail: neyneto@cesuca.edu.br

${ }^{3}$ BLOOM, Harold. Shakespeare: a invenção do humano. Tradução de José Roberto O'Shea. Rio de Janeiro: Objetiva, 2000, p. 222-245.

${ }^{4}$ Idem, p. 222-223.
} 
Marlowe em 1593-1594 a colocar em cena o dramaturgicamente bem sucedido Judeu de Malta, cuja personagem central, Barrabás, poderia ser comparada a Shylock. ${ }^{5}$

Regressando ainda alguns anos, Bárbara Heliodora menciona "A balada da crueldade", de Geruntus, anterior a 1590, e "O orador", coletânea de orações, dentre as quais está "De um judeu, que queria, por uma dívida, obter uma libra de carne de um cristão" 6 . Marilise Rezende Bertin ${ }^{7}$, por sua vez, sublinha que era usual o fato de contos serem reaproveitados para o teatro por outros autores, numa forma de releitura. Refere que havia uma novela que reunia essa parte do enredo e a outra, da disputa da mão de uma bela dama, na história de Gianetto, na coletânea italiana "Il Pecorone", possivelmente organizada por Ser Giovanni Fiorentino, duzentos anos antes de Shakespeare.

Quanto à linha de construção das comédias shakesperianas, considera Bertin ${ }^{8}$ que o ponto principal não se limita somente às relações entre famílias e amigos. Nesta obra, o autor analisa as relações da sociedade de um modo muito próximo. O mote é uma rede de obrigações construída no âmbito de um povo, que vai mais além de comercializar bens e acumular dinheiro. Tudo é emprestado e cobrado. A obra também aborda a questão do preconceito religioso com relação aos judeus. Eles não podiam exercer o comércio e por isso cobravam juros sobre o dinheiro que emprestam. Viviam isolados da sociedade. Havia uma revolta silenciosa dos judeus, que é representada por Shylock. Há um confronto, na peça, entre Antônio, o mercador cristão, e Shylock, onde cada um enfatiza a justiça segundo os seus interesses próprios.

Da análise desta marcante comédia, para fins de aproximar as relações entre o direito e a literatura, colocaremos em destaque o aspecto da multa prevista no contrato de empréstimo entre Shylock e Antônio. Trata-se de examinar, a partir de uma leitura jusfilosófica, a problemática envolvendo a escandalosa cláusula segundo a qual o credor poderia extrair um pedaço de carne do corpo do devedor, em torno de meio quilo, o equivalente a uma libra, se houvesse inadimplência. $O$ aspecto fundamental de nossa análise está em questionar se é juridicamente e moralmente admissível essa espécie de

\footnotetext{
${ }^{5}$ Idem, p. 223. Embora a temática fosse conhecida, Harold Bloom assevera que a questão judaica, nos termos da modernidade, era desconhecida por Shakespeare. Apenas cem ou duzentos judeus, a maioria presumivelmente convertida ao cristianismo, viviam em Londres. Isso porque, como assevera Bloom, os judeus haviam sido, de certa maneira, expulsos da Inglaterra em 1290 e só retornariam a ela quando da revolução de Cromwell.

${ }^{6}$ SHAKESPEARE, William (1564-1616). O mercador de Veneza: peça em cinco atos. Tradução de Barbara Heliodora. Rio de Janeiro: Nova Fronteira, 2011, p. 8.

${ }^{7}$ BERTIN, Marilise Rezende. O mercador de Veneza/William Shakespeare; tradução e adaptação de Marilise Rezende Bertin. São Paulo: Sipione, 2010, p. 6.

${ }^{8}$ Idem, p. 6.
} 
pacto. O tema, aliás, mostra-se atualíssimo. As discussões sobre os limites morais do mercado estão na pauta do dia nos debates e estudos de filosofia do direito.

\section{O Problema Jurídico - os limites da cláusula penal}

Podemos perceber na peça várias dimensões jurídicas, como a do testamento e do casamento, do estatuto dos estrangeiros, do direito processual, mas a principal de todas, que está no "coração da discussão", como enfatiza François Ost, é o contrato de mútuo e a sua cláusula penal. ${ }^{9}$

$\mathrm{Na}$ circunstância inaugural da peça, Antônio arrisca-se a ter uma libra de carne cortada de seu corpo para conseguir o dinheiro para financiar a corte de Bassânio a Pórcia. No diálogo travado, por ocasião do pedido de empréstimo, Shylock faz a sua proposta, dizendo que o fazia apenar por brincadeira. Na verdade, conforme surgirá no decorrer da trama, ele dissimulou sua real intenção e desejo, de que o devedor não conseguisse quitar a obrigação e que a multa fosse executada.

Transcrevemos o trecho da proposta feita por Shylock, na Cena III do Ato I:

Shylock: Eu a mostrarei,
Se for comigo ao notário e lá selar
Um compromisso simples que dirá
(Por brincadeira) que se não pagar
Em certo dia e local a soma ou somas
Mencionadas na nota, a multa imposta
Fica arbitrada numa libra justa
De sua carne alva, a ser cortada
E tirada da parte de seu corpo
Que na hora da escolha me aprouver. ${ }^{10}$

Antônio, o mercardor que dá nome ao título da peça, aquiesceu sem titubear, não porque esse tipo de penalidade pudesse ser admitida como normal, mas pelo excesso de confiança que depositava no retorno de seus navios mercantes, os quais the trariam os recursos para quitar a obrigação com folga e antecipadamente. Chegando a notícia de que os seus navios haviam afundado, Shylock dá início ao processo para ver cumprida a pena estipulada.

Cabe questionar se uma cláusula como esta, proposta por Shylock, tem algum precedente histórico. Seguindo a orientação de François Ost, começaremos por um

\footnotetext{
${ }^{9}$ OST, François. "Le marchand de Venice: Le pari et la dette, le jeu et la loi". Les Cahiers de Prospéro, Vol. $\mathrm{n}^{\mathrm{o}} 1$ - Faire langage-image I - Shakespeare et le droit, Shakespeare en Images, 2010, p. 63.

${ }^{10}$ SHAKESPEARE, William (1564-1616). O mercador de Veneza: peça em cinco atos. Tradução de Barbara Heliodora. Rio de Janeiro: Nova Fronteira, 2011, p. 32.
} 
exame da lei de talião e pela Lei das XII tábuas. ${ }^{11}$ A lei de talião encontra a primeira formulação no Êxodo e posteriormente no Levítico e no Deuteronômio. Os comentadores talmúdicos criticam as interpretações cristãs dessas passagens, pois elas revelam muito mais uma busca da compensação equillibrada do dano, mais frequentemente financeira, a ser quantificada em cada caso diante do tribunal rabínico. No Levítico $(19,18)$, encontramos a proibição da vingança e a exigência de não guardar rancor contra o próximo. A uma primeira vista, a cláusula de Shylock não parece encontrar amparo na tradição judaica.

A partir de outra importante fonte, a Lei das XII tábuas, que é o primeiro corpo do direito civil romano, encontramos na terceira tábua uma relação de regras para os devedores inadimplentes, das quais destaca-se a seguinte: "Depois do terceiro dia de feira, que ele seja cortado em partes. Se the é retirado mais do que o devido, que isso se faça sem punição". Aí está provavelmente a passagem que pode ter inspirado Shakespeare, segundo a leitura de François Ost. ${ }^{12}$ No entanto, também é importante lembrar que, ao que tudo indica, esta regra não chegou a ser efetiva, tendo sido discutida desde a Antiguidade. Ou seja, os textos legais da tradição judaica e da tradição romana não comportam uma justificação da referida cláusula.

Além disso, temos de lembrar que, na época de Shakespeare, a Corte de Chanceleria liberava em muitos casos os devedores das penalidades pecuniárias estipuladas nos contratos e uma nova literatura aparecia para criticar o formalismo jurídico. ${ }^{13}$ Podemos ainda nos perguntar se Shakespeare tinha algum conhecimento do direito veneziano e, ao que tudo indica, o seu conhecimento era apenas aproximativo. Contrariamente ao caso de Antônio, as embarcações venezianas eram muito bem seguradas. Ao final do séc. XIV, Veneza tornou-se o principal centro mundial do seguro marítimo. ${ }^{14}$ Certamente, portanto, já na época de Shakespeare, uma cláusula penal exigindo pagamento em libra de carne não encontrava guarida jurídica. Não havendo nenhuma possibilidade de sustentação real dessa cláusula, o estereótipo Shylock parece suscitar um curioso sentimento de inversão, reforçado por uma impressão de negação da realidade, como indaga François Ost, acerca da injusta e atroz pena imposta ao médico da Rainha Elizabeth, o Dr. Lopez: "como se o público elizabetano tivesse necessidade de descarregar sobre um odioso Shylock imaginário um enorme sentimento de culpabilidade reprimida".

\footnotetext{
${ }^{11}$ OST, François. "Le marchand de Venice: Le pari et la dette, le jeu et la loi”. Les Cahiers de Prospéro, Vol. $\mathrm{n}^{\mathrm{o}} 1$ - Faire langage-image I - Shakespeare et le droit, Shakespeare en Images, 2010, p. 60.

${ }^{12}$ Idem, p. 61.

${ }^{13}$ Idem, p. 61.

${ }^{14}$ Idem, p. 62.
} 
Trazendo para o contexto atual, caso tivéssemos de avaliar esta cláusula, a nossa interpretação é de que ela contraria direitos humanos, direitos constitucionais fundamentais e direitos civis. No campo dos direitos humanos, destaca-se a proteção da dignidade e proteção nos art. I e V da Declaração de Direitos Humanos da ONU (1948). Assim determina o art. V: "Ninguém será submetido à tortura nem a tratamento ou castigo cruel, desumano ou degradante". No âmbito do sistema jurídico brasileiro, a previsão desta cláusula penal viola a Constituição da República, que garante o respeito à dignidade da pessoa humana no seu art. $1^{\circ}$, inc. III, como preceito fundamental. Ainda, como afirma Judith Martins-Costa, há na Constituição Federal a previsão de princípios que conduzem ao fim preciso do art. $3^{\circ}, \mathrm{I}$ - a sociedade solidária - o que se estabelece pela relação íntima entre mercado e solidariedade social. ${ }^{15}$

Além disso, identificando a transformação paradigmática operada pela concepção da obrigação como processo, podemos afirmar, na esteira de Judith Martins-Costa, que o direito obrigacional deixa de estar baseado exclusivamente no dogma da vontade, passando a se fundamentar na boa-fé objetiva. ${ }^{16}$ É evidente que o contrato assinado já com a finalidade prévia de aplicar uma penalidade brutal atenta contra a boa-fé esperada nos contratos, contrariando a sua função social.

No campo infraconstitucional, o próprio Código Civil Brasileiro dispõe em seu art. 421 que a liberdade de contratar será exercida em razão e nos limites da função social do contrato, colocando limites na liberdade dos contratantes. E o contrato com a multa em questão viola direito indisponível, da personalidade. Na dicção do art. 13 do Código Civil é defeso, salvo por exigência médica, o ato de dispor do próprio corpo, quando importar diminuição permanente da integridade física ou contrariar os bons costumes.

\section{O Problema moral - os limites do mercado}

O segundo movimento de nossa análise consiste em avaliar a estipulação da cláusula penal do contrato entre Shylock e Antônio desde uma perspectiva filosófica. Tomaremos como base de nossa reflexão a contribuição do renomado professor de filosofia da Universidade de Harvard, Michael J. Sandel ${ }^{17}$, que no seu curso "Justice" levanta importantes questionamentos acerca dos limites morais do mercado. Muitas

\footnotetext{
${ }^{15}$ MARTINS-COSTA, Judith. "Mercado e solidariedade social entre Cosmos e Taxis: a boa-fé nas relações de consumo". MARTINS-COSTA, Judith (Org.) A reconstrução do direito privado. São Paulo: Revista dos Tribunais, 2002, p. 620.

${ }^{16}$ MARTINS-COSTA, Judith. A boa-fé no direito privado. São Paulo: Revista dos Tribunais, 2000, p. 394.

${ }^{17}$ SANDEL, Michael J. Justiça - O que é fazer a coisa certa. $4^{\mathrm{a}}$. ed. Tradução de Heloísa Matias e Maria Alice Máximo. Rio de Janeiro: Civilização Brasileira, 2011, pp. 77-131.
} 
discussões sobre justiça envolvem o papel dos mercados. O livre mercado é justo? Existem bens que o dinheiro não pode comprar - ou não deveria comprar? Caso existam, que bens são esses e o que há de errado em vendê-los? São discussões entre liberdade (filosofia libertária) e bem-estar social (filosofia utilitarista) que Sandel traz à baila, para quem certos bens e práticas sociais são corrompidos ou degradados se implicarem alguma transação com dinheiro.

Sandel levanta a questão a respeito do consentimento comprometido. Tem a ver com a questão sobre as condições nas quais as pessoas fazem escolhas. Nossas escolhas são livres se não estivermos sob excessiva pressão (por exemplo, por necessidade financeira) e se estivermos razoavelmente informados sobre todas as alternativas. No exemplo da pela em comento, o mercador Antônio, no afã de ajudar seu amigo que necessitava do dinheiro, não avaliou de modo lúcido os riscos que estava correndo ao anuir com a multa cominada por Shylock.

Além disso, existem certas coisas que o dinheiro não deveria comprar. Isso nos traz o segundo questionamento: somos proprietários de nós mesmos? Para avaliar se Antônio poderia dispor de meio quilo de carne do seu corpo, poderíamos traçar um comparativo com a possibilidade ou não de venda de órgãos humanos para transplantes. A maioria dos países proíbe a prática. Nos Estados Unidos, pode-se doar um dos rins, mas não se pode vendê-lo. Alguns sustentam que as pessoas deveriam ser livres para vender seus rins. Opor-se a essa liberdade significa que não temos um direito de propriedade ilimitado sobre nossos corpos.

Um exemplo extremo, trazido para a reflexão por Sandel, é o caso de canibalismo consensual ocorrido em 2001, na Alemanha. Armin Meiwes queria que alguém o matasse e que o comesse. Publicou um anúncio e o acordo foi fechado com Brandes, que consumou o plano e foi condenado à prisão perpétua.

A discussão sobre o papel dos mercados é aprofundada na segunda obra de Michael J. Sandel ${ }^{18}$, a respeito dos seus limites morais. Para o filósofo, há circunstâncias em que o mercado faz sentido e outras nas quais deveria ser mantido à distância. Nas três últimas décadas, os valores de mercado passaram a governar nossa vida como nunca. Quando a guerra fria acabou, o pensamento pautado pelo mercado passou a desfrutar de prestígio sem igual. Os mecanismos de mercado passaram a gerir a economia dos países. Os valores de mercado passaram a desempenhar um papel cada

\footnotetext{
18 SANDEL, Michael J. O que o dinheiro não compra: os limites morais do mercado. Tradução de Clóvis Marques. Rio de Janeiro: Civilização Brasileira, 2012, pp. 09-20. 
vez maior na vida social. A lógica de compra e venda não se aplica mais apenas a bens materiais, governa a vida como um todo.

Essa era começou no início da década 1980, quando Ronald Regan e Margaret Tatcher proclamaram sua conviç̧ão de que os mercados, e não o governo, é que detinham a chave da prosperidade e da verdade. Prosseguiu nos anos $1990 \mathrm{com}$ Bill Clinton e Tony Blair, com a convicção de que os mercados constituem o principal meio para a consecução do bem público. Essa era chegou ao fim com a crise financeira de 2008. Pôs em dúvida a capacidade dos mercados de gerir riscos com eficiência. Generalizou também a impressão de que os mercados desvincularam-se da moral e de que precisamos restabelecer esse vínculo. Alguns acham que a ganância levou a assumir riscos de maneira irresponsável e que a solução seria coibi-la.

Para Sandel, há algo maior que isso em questão: a extensão dos mercados e seus valores a esferas da vida com as quais nada têm a ver. Precisamos repensar os limites morais do mercado. Há certas coisas que o dinheiro não pode comprar. Uma sociedade em que tudo está à venda gera problemas de desigualdade e de corrupção. A vida fica mais difícil para os que dispõem de recursos modestos.

Há dois obstáculos quando se tenta repensar o papel dos mercados: o poder e o prestígio do pensamento de mercado e a animosidade e o vazio do discurso público. A crise do discurso público impede o debate sobre os limites morais do mercado. O vazio moral da política tem a ver com a não discussão de questões dos ideais. Para evitar confrontos sectários, a arena pública não enfrenta questões morais e religiosas. Isso abriu espaço para o triunfo do mercado e sua lógica.

O interesse do mercado não julga as preferências a que atende. Não discriminam entre preferências louváveis ou condenáveis. Nossa relutância em aceitar os argumentos morais e espirituais privou o discurso público de energia moral e cívica, prevalecendo a lógica do mercado. A análise dos limites morais dos mercados requer que pensemos juntos, em público, como atribuir valor aos bens sociais que prezamos. Vamos repensar o papel e o alcance do mercado em nossas práticas sociais, nas relações humanas e na vida cotidiana, é o convite que nos formula o filósofo de Harward, em sua provocativa análise da questão.

\section{Conclusão.}

O contrato celebrado entre Shylock e Antonio permite a discussão sobre a força vinculante e obrigatória dos contratos, consagrado na máxima "pacta sunt servanda" e os 
limites éticos da liberdade de contratar. Embora seja necessário o respeito à autonomia privada, essa não pode prevalecer quando houver grande desequilíbrio entre os direitos e as obrigações das partes. As situações de grande necessidade ou de inexperiência do contratante, ou do perigo de grave dano que esta corra, são exemplos que permitem a revisão do que foi avençado.

Considerando a cláusula penal no contexto jurídico atual, podemos afirmar que ela feriria direitos humanos e violaria direitos fundamentais e direitos da personalidade. Além disso, no que tange ao aspecto moral, o contrato extrapolaria os limites dentro dos quais todo mercado deve ser compreendido.

Enfim, é importante reforçar que há coisas que o dinheiro não compra. Vivemos numa sociedade capitalista, com exagerado consumismo e de valorização dos bens materiais. A discussão sobre os limites do mercado e da liberdade de contratar, orientada pela temática da peça, é bastante ilustrativa e importante para se mostrar que o homem não pode se tornar mero objeto e o mercado não lhe pode tirar a sua dignidade.

\section{Referências}

SHAKESPEARE, William, 1564-1616. O mercador de Veneza: peça em cinco atos. Tradução Barbara Heliodora. Rio de Janeiro: Nova Fronteira, 2011.

BERTIN, Marilise Rezende. O mercador de Veneza/William Shakespeare. Tradução e adaptação de Marilise Rezende Bertin. São Paulo: Sipione, 2010.

BLOOM, Harold. Shakespeare: a invenção do humano. Tradução de José Roberto O'Shea. Rio de Janeiro: Objetiva, 2000.

MARTINS-COSTA, Judith. A boa-fé no direito privado. São Paulo: Revista dos Tribunais, 2000.

- "Mercado e solidariedade social entre Cosmos e Taxis: a boa-fé nas relações de consumo". MARTINS-COSTA, Judith (Org.) A reconstrução do direito privado. São Paulo: Revista dos Tribunais, 2002, p. 611-661.

OST, François. "Le marchand de Venice: Le pari et la dette, le jeu et la loi". Les Cahiers de Prospéro, Vol. $\mathrm{n}^{\circ} 1$ - Faire langage-image I - Shakespeare et le droit, Shakespeare en Images, 2010, p. 68-80.

SANDEL, Michael J. Justiça - O que é fazer a coisa certa. $4^{\mathrm{a}}$. ed. Tradução de Heloísa Matias e Maria Alice Máximo. Rio de Janeiro: Civilização Brasileira, 2011.

. O que o dinheiro não compra: os limites morais do mercado. Tradução de Clóvis Marques. Rio de Janeiro: Civilização Brasileira, 2012, pp. 09-20.

(Artigo submetido em 04/12/2013 e aceito para publicação em 30/12/2013) 